Gut, 1982, 23, 31-35

\title{
Role of autologous lymphocyte cytotoxicity in colonic neoplasia*
}

\author{
P GALLAGHER, B M VOSE, M MOORE, AND P F SCHOFIELD \\ From Withington Hospital, Manchester, Department of Immunology, Paterson Laboratories, Christie Hospital, \\ and Holt Radium Institute, Manchester
}

SUMMARY The T-lymphocyte mediated killing of autologous carcinoma colon cells was investigated. There was no change in the incidence of activity with advanced disease, age, or nutritional status of the patient and no difference could be demonstrated in lymphocytes extracted from blood, draining lymph nodes, or the tumour itself. Nevertheless, T-lymphocyte activity did appear to be specific for the patient's own tumour, as it was rarely observed with allogeneic tumours. There was also no correlation with lymphocyte natural killer activity. The in vitro studies demonstrated patient specific T-lymphocyte activity in 23 of 47 patients with carcinoma of the colon, but the results do not correlate with clinical and pathological findings.

Phenomena such as the infiltration of tumours by lymphocytes and macrophages ${ }^{12}$ suggest an immunological host defence against neoplasia. Several distinct types of lymphocyte/tumour cell interaction are now well recognised. ${ }^{3}$ The activity shown by T-lymphocytes and by lymphoid natural killer (NK) cells have been implicated in the immuno-surveillance of tumours. Previous studies of a cytotoxic lymphocyte effect have concentrated on activity against tumour cells derived from other patients. Under these conditions our own studies and those of several others failed to discriminate between the lytic potential of lymphocytes from patients with malignancy and lymphocytes from either healthy individuals or patients with other disease. ${ }^{45}$ Patterns of activity were consistent with those induced by 'natural killer' cells which have the capacity to lyse cell lines without apparent regard to either histocompatibility or to the previous known immunological experience of the donor 6 . With such high background non-specific killing no disease-related lysis was apparent. However, localisation experiments have indicated that specifically sensitised cells will home to the site of an antigenic challenge and to the local draining lymph nodes with a corresponding depletion in blood and nondraining nodes. ${ }^{7}$

\footnotetext{
* This study was supported by grants from the Cancer Research Campaign and the Medical Research Council of Great Britain.

tAddress for correspondence: $P$ Gallagher, Teaching Unit 5. Withington Hospital, West Didsbury. Manchester 20.

Received for publication 8 June 1981
}

The present study investigates specific lymphocyte activity in colonic neoplasia. The lymphocyte-mediated killing of autologus carcinoma cells was compared with the killing of cells from allogeneic colonic tumours and a non-colonic line showing extreme sensitivity to lysis by NK cells (K562).

The activity of lymphocytes extracted from different sites in the patient, including the tumour itself, and the influence of the pathological staging of the disease were also examined.

\section{Methods}

PAT IENTS

Material was collected from patients presenting with resectable carcinoma of the colon. Forty millilitres of venous blood were collected in heparinised tubes immediately before administration of anaesthetic premedication. After resection a full thickness segment of tumour was removed, together with several draining lymph nodes in the colonic mesentery. The nodes were separated into two groups: those close $(1-2 \mathrm{~cm})$ to the tumour and those at the base of the mesentery and at least $6 \mathrm{~cm}$ from the tumour. All specimens were examined histologically and staged according to Dukes's classification. Blood lymphocytes were also prepared from samples from 15 known healthy laboratory personnel (age 23-37 years).

\section{TUMOUR}

The tumour specimen was finely chopped with scalpels and stirred for three hours in an enzyme mixture 
containing collagenase $(0 \cdot 2 \%)$, hyaluronidase $(0.01 \%)$, and DNAase $(0.01 \%)$. Tumour cell suspensions were freed of remaining dead cells, red cells, and polymorphs by centrifugation on gradients of lymphocyte separation medium (Flow Laboratories, Irvine, Scotland) followed by incubation in plastic culture flasks as described before. ${ }^{8}$ Cells were then placed on a discontinuous gradient of $6 \mathrm{ml} \mathrm{lym}$ phocyte separation medium overlaid with $6 \mathrm{ml}$ of a $3: 4$ dilution of this. After centrifugation $(1400 \mathrm{~g}$ for 15 minutes at $4^{\circ} \mathrm{C}$ ) two interfaces were apparent: an upper interface consisting primarily of tumour cells and a lower interface containing lymphocytes with minimal contamination by tumour cells. The two interfaces were removed by pipette. The tumour cells were used as targets. The lymphocyte layer was run into columns of nylon fibre $(0.6 \mathrm{~g}$ scrubbed nylonFenwal Laboratories, Illinois) in $5 \mathrm{ml}$ syringes with a $19 \mathrm{G}$ needle attached. These columns were incubated at $37^{\circ} \mathrm{C}$ for 30 minutes and non-adherent cells eluted with $10 \mathrm{ml}$ tissue culture medium. Tumour cells remained attached to the column with $T$-enriched lymphocyte populations in the eluted suspension: $65-80 \%$ of the cells in this suspension formed rosettes with sheep red blood cells. Such rosette formation is a property of T-lymphocytes.

\section{BLOOD AND LYMPH NODES}

Lymphocytes were isolated from blood also by centrifugation on lymphocyte separation medium. Lymph node tissue was minced with scissors and passed through a 200 mesh steel grid. Lymphocytes were removed from the resultant cell suspension as for the blood. Both populations consisted of cells, $57-68 \%$ of which formed rosettes with sheep red blood cells. In further fractionation studies some lymphocyte populations from blood and lymph node were enriched for T-cells by passage through nylon wool columns as described above.

\section{CELL LINE}

The $\mathrm{K} 562$ cell line ${ }^{9}$ was maintained in suspension culture in tissue culture medium. This cell line was used to monitor levels of natural killer activity (NK) in lymphocyte populations because of its extreme sensitivity to lysis by this mechanism.

\section{CYTOTOXIC ASSAYS}

Cytotoxic assays were designed in such a way that lymphocytes were set up against autologous tumour cells and, where possible, at least one other fresh allogeneic tumour. The number of cross tests depended upon the availability of allogeneic targets. Target cells $\left(1 \times 10^{6}\right.$ in $0.5 \mathrm{ml}$ tissue culture medium) were labelled by the addition of $100 \mu \mathrm{Ci}$ sodium ${ }^{51} \mathrm{Cr}$ chromate (Radiochemical Centre, Amersham, UK) as described before. ${ }^{8}$ Lymphocytes were added to $5 \times 10^{3}$ target cells to give lymphocyte target ratios between $50: 1$ and 10:1. The fluid volume was adjusted to $0.4 \mathrm{ml}$, centrifuged ( $80 \mathrm{~g}$ for five minutes) and incubated at $37^{\circ} \mathrm{C}$ for four hours before the removal of $0.2 \mathrm{ml}$ of the supernate. The radioactivity in these samples and in the remaining pellets and supernates was measured in a gamma counter. Spontaneous release of ${ }^{51} \mathrm{Cr}$ was measured in tubes containing target cells without lymphocytes, while maximum ${ }^{51} \mathrm{Cr}$ release was measured after all the target cells were lysed with the detergent Triton $\times 100$ (Sigma Chemical Company). Percentage ${ }^{51} \mathrm{Cr}$ release was calculated for each tube from the formula:

$$
\%{ }^{51} \mathrm{Cr} \text { release }=\frac{2 \times \text { supernate sample count }}{\text { Supernate sample }+ \text { pellet count }} \times \frac{100}{1}
$$

and cytotoxicity derived.

$$
\begin{aligned}
& \% \text { cytotoxicity }= \\
& =\frac{\%{ }^{51} \mathrm{Cr} \text { release test }- \text { spontaneous }{ }^{51} \mathrm{Cr} \text { release }}{\text { maximum }{ }^{51} \mathrm{Cr} \text { release }- \text { spontaneous }{ }^{51} \mathrm{Cr} \text { release }} \times \\
& \times \frac{100}{1}
\end{aligned}
$$

Cytotoxicity was considered positive when mean \% ${ }^{51} \mathrm{Cr}$ release exceeded spontaneous release by at least three standard deviations. Significance was assessed by the Mann-Whitney U test on replicate samples.

\section{Results}

Lymphocytes from 47 patients were tested for cytotoxicity against autologous colon tumour cells. The $M: F$ sex ratio of the patients was approximately 0.9 and the mean age was 73.5 years with a range of 59-89 years. Dukes's staging of the tumour showed one stage $A, 24$ stage $B, 15$ stage $C$, and seven stage $C$ with distant metastases. Overall, 23 of 47 patients exhibited significant lytic activity in at least one lymphocyte population. In the majority of these ( 15 of 23 ) lymphocytes from several sites in the patient were cytotoxic against autologous cells. In five patients lytic potential was limited to blood and in three to lymph node.

The 23 patients with positive lymphocyte cytotoxicity had a mean age of 76 years (range 60-89 years) and a $M: F$ sex ratio of 0.5 , whereas the remainder had a mean age of 71 years (range 59-85 years) and a $M: F$ sex ratio of $1 \cdot 5$. Cytotoxicity appears to be more prevalent among females, but is not affected by advancing years. Serum albumen levels were estimated before operation and used as a guide to the nutritional status of the patient. Levels were low in six of the patients - three in the active group and three in the non-active group. Figure 1 demonstrates the activity of lymphocytes isolated from different sites in the patient 


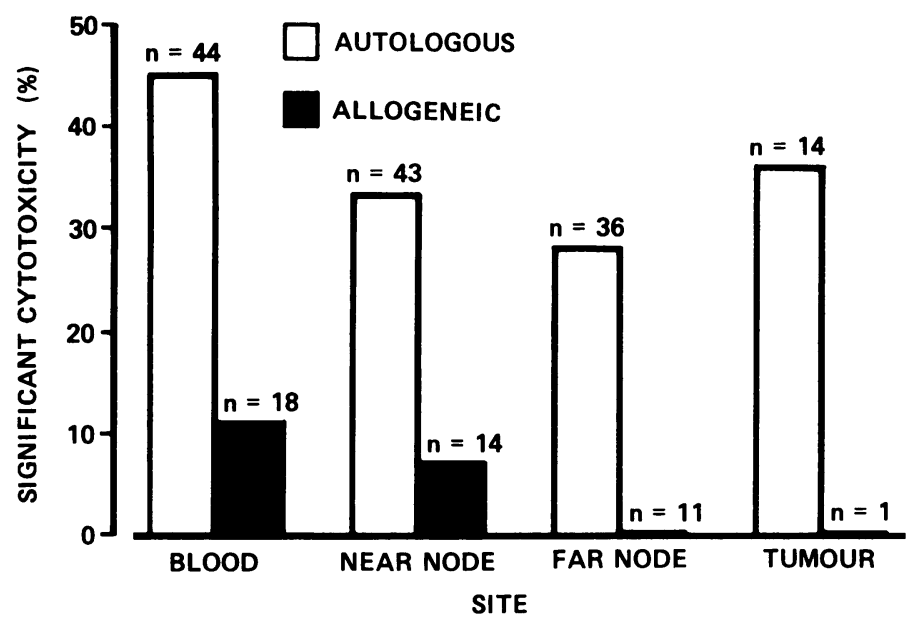

Fig. 1 Percentage of patients with significant lymphocyte cytotoxicity against autologous and allogeneic carcinoma cells.

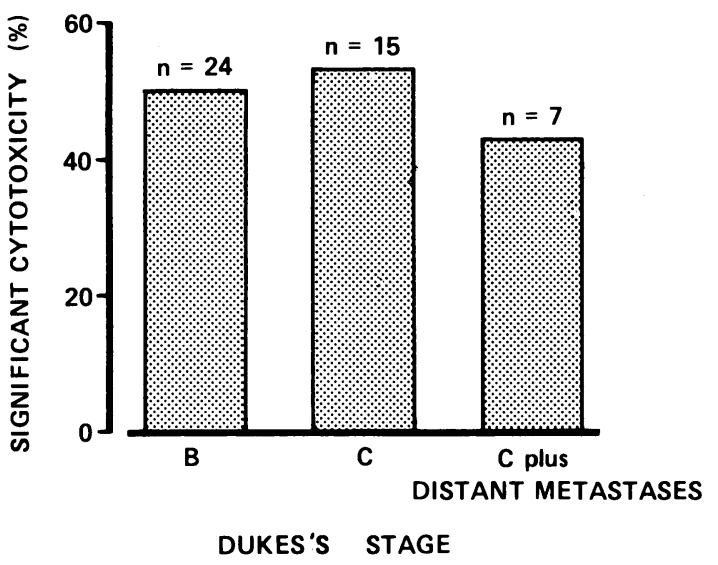

Fig. 2 Percentage of patients with significant lymphocyte cytotoxicity against autologous carcinoma cells in Dukes's B, Dukes's $C$, and metastatic tumours.

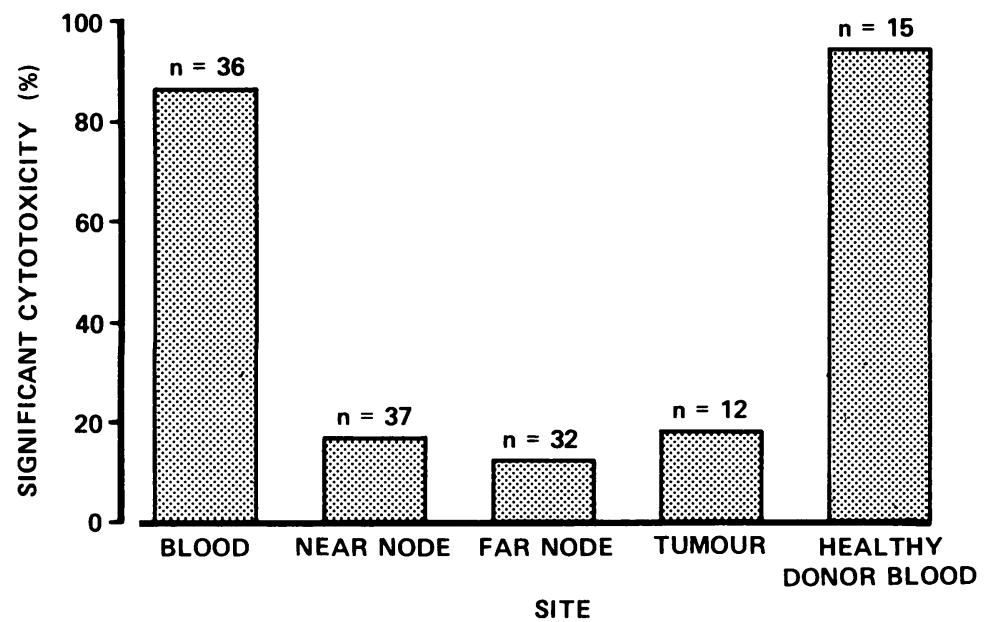

Table Range of significant percentage cytotoxicity

\begin{tabular}{lcccc}
\hline & Blood & Near node & Far node & Tumour \\
& & & & \\
$\begin{array}{l}\text { Autologous } \\
\text { combination }\end{array}$ & $8.5-50.4$ & $12.0-37.1$ & $8.4-41.4$ & $10.4-72.6$ \\
$\begin{array}{l}\text { Allogeneic } \\
\text { combination }\end{array}$ & $13.9-14.9$ & 14.5 & & \\
Healthy donor & $12.7-22.4$ & - & & \\
\hline
\end{tabular}

Cytotoxicity was considered significant when mean $\% 51 / \mathrm{Cr}$ release exceeded spontaneous release by at least three standard deviations.

against autologous tumour and allogeneic colon tumour. There is no significant difference in the activity of lymphocytes from blood, near node, far node, or tumour. However, there is a marked difference in each case between the activity against autologous cells and the activity against allogeneic cells (Table). This suggests that the cytotoxicity being measured was mainly specific for the patient's own tumour cells. Healthy

Fig. 3 Percentage of patients and healthy controls with significant lymphocyte cytotoxicity against the K562 cell line. 
donor blood lymphocytes showed significant activity in three of 12 cases. In comparing the number of patients with active lymphocytes in different stages of disease (Fig. 2) there is no clear evidence of a fall in activity with advancing disease. (Lymphocytes from the single case in Dukes's stage A showed no activity against the tumour cells).

Lymphocytes were also tested for cytotoxicity against the K562 cell line in order to determine the levels of 'natural killer' activity (Fig. 3). The lysis of K562 targets was apparent in the majority of blood lymphocytes from both healthy donors $(14 / 15)$ and colon cancer patients $(31 / 36)$. Comparison of the cytotoxic potential of blood lymphocytes from patients with different stages of disease revealed no difference in activity. In contrast with the activity of lymphocytes against autologous cells, lymphocytes from draining lymph.nodes and the tumour mass rarely lysed K562 cells. Although lymphocytes from blood were frequently active against both autologous tumour and $\mathrm{K} 562$, there was no significant correlation in the degree of activity. Attempts to characterise the cytotoxic lymphocytes in blood and lymph node were made by enrichment of T-lymphocytes by passage through nylon columns. This procedure enriched $\mathrm{T}$ cells from approximately $60 \%$ to greater than $85 \%$. In almost all cases the greatest cytotoxicity for autologous colon tumour cells was found in $\mathrm{T}$ cell enriched populations. In contrast, the highest killing of K562 resided in populations from peripheral blood which did not form rosettes with SRBC.

\section{Discussion}

In this study we have delineated two major lymphocyte populations with separate distinct functions: a nonspecific killer population displaying high activity against the K562 cell line and a relatively specific killer population which is preferentially active against autologous tumour cells. Natural killer activity is relatively non-specific and is also present in blood taken from healthy donors. This activity is not modified by advancing disease and remains high after metastatic spread of tumour. Activity against K562 is very poor, however, within the lymphatic system and the tumour itself. It would seem unlikely that 'natural killer' cells can play an active role in the control of established malignancy.

Lymphocyte cytotoxicity against autologous cells differs from natural killing in some important ways. The activity appears to be concentrated in T-lymphocytes, is largely specific for the patient's own tumour cells, only occurring in two of 18 allogeneic tumours and is present in blood, draining lymph nodes, and the tumour mass. Whether the lymphocyte activity seen in a minority of normal donors (three of 12 showed cyto- toxicity) is attributable to unusual NK like activity (tumour biopsy cells are mostly NK resistant ${ }^{10}$ ) or allospecific activity directed against histocompatibility antigens is unknown. In any event, the target cells against which these normal cells were active were also sensitive to autologous killing, which suggests that they were susceptible to lysis by several different mechanisms.

It may be suggested that autologous lymphocyte cytotoxicity plays a role in the control of tumour spread. Yet the activity was demonstrable in only 23 of 47 of the patients and there was no change in the incidence of activity with advanced disease, age, or nutritional status. These findings are similar to those of Nind et al. ${ }^{11}$ who demonstrated no significant correlation between lymphocyte activity and histopathological differentiation or dissemination of colonic tumours. Over the past 15 years humoral and cellmediated immunity against a variety of human tumours has been extensively studied. ${ }^{12}$ There is substantial evidence that immune reactivity against tumourassociated antigens does exist in many types of cancer. However, the observed reactivity has not been clearly related to extent of disease or prognosis and there is at present no good support for the contention that in vitro assays of tumour immunity reflect important events in the resistance of the host against progressive tumour growth. One major problem is that the immune response to tumours is multifactorial and complex, with possible involvement of several different types of humoral and cell-mediated mechanisms. In other words, T-lymphocyte activity represents only part of the immunological orchestra. The many variables affecting the processes of tumour growth make it difficult to formulate simple correlations from in vitro data.

Infiltration by lymphoreticular cells is a common feature of many human malignant neoplasms. ${ }^{13} \mathrm{We}$ do not know whether the infiltration is simply a consequence of immunological recognition of tumour cell surface antigens or whether the lymphoid cells influence the tumour growth. In the view of some, leucocytes may even be essential for tumour growth. However, the general consensus of opinion at the present time is that infiltrating inflammatory cells possess immunological and defensive functions. Svennevig and Svaar ${ }^{14}$ noted that lymphocytes are usually more numerous in the surrounding stroma than in the central areas of gastrointestinal tumours and it may be that these peripheral cells are important, as Werkmeister ${ }^{15}$ has shown significant association between intrinsic $T$ lymphocyte cytotoxicity and the presence of 'cuffs' of lymphocytes at the edge of colorectal cancers.

The biological role of lymphocytes in resistance to human tumours remains obscure. Nevertheless, the lymphocyte infiltration of tumours and the cyto- 
toxicity shown by these lymphocytes and those from blood and draining lymph nodes are intriguing in vitro realities and may well reflect part of the in vivo immune defence against cancer.

We are indebted to Mr R Ferguson for skilled technical assistance.

\section{References}

${ }^{1}$ Lauder I, Aherne W, Stewart J, Sainsbury R. Macrophage infiltration of breast tumours. J Clin Pathol 1977; 30:563-8.

${ }^{2}$ Husby G, Hoagland P, Strickland R, Williams R. Tissue T and $B$ cell infiltration of primary and metastatic cancer. J Clin Invest 1976; 57:1471-82.

3Perlmann P, Cerottini JG. Cytotoxic lymphocytes. In: Sela M, ed. The antigens. Vol 5. New York: Academic Press, 1979; 173-281.

${ }^{4}$ Takasugi M, Mickey MR, Terasaki PI. Reactivity of lymphocytes from normal persons on cultured tumour cells. Cancer Res 1973; 33:2898-902.

5Vose BM, Moore M, Schofield PF, Dymock IW, Leucocytotoxicity in malignant and non-malignant colonic diseases. Clin Exp Immunol 1975; 22:393-8.

6Herberman RB, Holden HT. Natural cell mediated immunity. Adv Cancer Res 1978; 27:305-77.
${ }^{7}$ Emeson EE. Migratory behaviour of lymphocytes with specific reactivity to alloantigens. J Exp Med 1978; 147:13-24.

8 Vose BM. Cytotoxicity of adherent cells associated with some human tumours and lung tissues. Cancer Immunol Immunother 1978; 5:173-9.

${ }^{9}$ Lozzio CB, Lozzio BB. Cytotoxicity of a factor isolated from human spleen. J Natl Cancer Inst 1973; 50:535-8.

10Vose BM, Moore M. Natural cytotoxicity in humans: susceptibility of freshly isolated tumour cells to lysis. $J$ Natl Cancer Inst 1980; 65:257-63.

11 Nind APP, Nairn RC, Rolland JM, Guli EPG, Hughes ESR. Lymphocyte anergy in patients with carcinoma. $\mathrm{Br} J$ Cancer 1973; 28:108-117.

${ }^{12}$ Herberman RB. Existence of tumour immunity. In: Cohen S, and Green I, eds. Mechanisms of tumour immunity. New York: John Wiley, 1977; 175-91.

${ }_{13}$ Underwood JCE. Lymphoreticular infiltration in human tumours: prognostic and biological implications: a review. Br J Cancer 1974; 30:538-547.

${ }^{14}$ Svennevig JL, Svaar H. Content and distribution of macrophages and lymphocytes in solid malignant human tumours. Int J Cancer 1979; 24:754-58.

15Werkmeister JA, Pihl E, Nind APP, Flannery GR, Nairn RC. Immunoreactivity by intrinsic lymphoid cells in colorectal carcinoma. Br J Cancer 1979; 40:839-47. 